\title{
An Analysis of the Affective Disorders (Revised Hypothesis) Theresa Hannon*
}

Graduate Open University, Science 31 Meadowbank Street, Belfast, N.I. BT9 7FG, UK

*Corresponding author: Theresa Hannon, Graduate Open University, Science 31 Meadowbank Street, Belfast, N.I. BT9 7FG, UK, Tel: 007411748477, 00442890666124; E-mail: eugene.hannon@live.co.uk

Received date: June 24, 2016; Accepted date: July 20, 2016; Published date: July 26, 2016

Copyright: (c) 2016 Hannon T. This is an open-access article distributed under the terms of the Creative Commons Attribution License, which permits unrestricted use, distribution, and reproduction in any medium, provided the original author and source are credited.

\begin{abstract}
The principal purpose of this Study is to assert that either or both of the Prokineticins fail to be degraded in the case of the Affective Disorders. Although genetic defects in PROKR2 (the Gene responsible for synthesizing Prokineticin 2 Receptor protein) are usually associated with Kallmann Syndrome, this study intends to indicate that the Single Nucleotide Polymorphism (SNP) rs6053303 was homozygous in 4 out of 7 Affective Disorder Genomes. Concerning Kallmann Syndrome, Dode $\mathrm{C}$ et al. have noted that this Disorder is caused by insufficient prokineticinsignalling through PROKR2. By comparison, Hannon proposes that the Affective Disorders may be caused by PROKR2's failure to degrade either or both of the Prokineticins.

Other Researchers have found that exogenous mRNA can be internalized by cells and translated into functioning protein. PROKR2 mRNA has been sequenced (NCBI, 'Nucleotide', NM_144773.2); arguably this could be used to restore function to the Prokineticin 2 Receptor and thereby control both of the Affective Disorders (Endogenous Depression and Bipolar Disorder).
\end{abstract}

Keywords: Affective disorder; Endogenous depression; Bipolar disorder; Behaviour

\section{Introduction}

In 2002, Cheng et al. [1] found that Prokineticin 2 transmits the behavioural circadian rhythm of the suprachiasmatic nucleus of the hypothalamus [1]. Also in 2002 the receptors for prokineticin 1 and 2 were characterised by [2]. Soga et al. [2] also noted in this article that the Prokineticin 2 Receptor is preferentially expressed in the Central Nervous System. Martin et al. [3] in his Research 'The Role of The Prokineticin 2 Pathway in Human Reproduction.' has noticed that the Prokineticin 2 Receptor binds both Prokineticins 1 and 2 (see pages 232-233).

In 2009 Kishi et al. [4] elucidated an association of the prokineticin 2 receptor gene (PROKR2) with mood disorders in the Japanese population. Also in 2009, Li et al. [5] discovered that disruption of prokineticin 2 results in Depression-like behaviour in mice. Hannon would suggest that Prokineticins 1 and 2 is an antagonistic pair; Prokineticin 2 may induce Depression in the Central Nervous System, while Prokineticin 1 may induce Mania. ELISA Kits for Prokineticin 1 and Prokineticin 2 are commercially available; these should reveal an excess in the circulation of either of the Prokineticins in patients suffering from either of the Affective Disorders [6,7].

More recently, the Personal Genome Project has made a few Human Affective Disorder (both Bipolar Disorder and Major Depression) Genomes publicly available; Theresa Hannon has analysed (in silico) the Single Nucleotide Polymorphisms found in the PROKR2 Gene coding for the Prokineticin 2 Receptor (NCBI: NC_000020.11, chromosome 20, range: 5299874..5317547).

Hannon found that the SNP rs6053303 was present and homozygous in 2 out of 4 of the Bipolar Disorder Genomes, and the same SNP rs6053303 was present and homozygous in 2 out of the 3 Major Depression Genomes studied (position: 5300088). However, Theresa Hannon's study has only involved 7 Human Affective Disorder Genomes, and so these findings must be regarded as extremely tentative.

\section{Results and Discussions}

Hannon's In Silico Analysis involved noting all the SNPs present on Chromosome 20 (within the range 5299874..5317547; NCBI's Accession Number for this is NC_000020.11) in all the available Personal Genome Project Genomes (3 Major Depression Genomes, 4 Bipolar Disorder Genomes, and 3 Control (symptomless) Genomes). SNPs that were also present in the Control (symptomless) Genomes were ruled out, leaving just one SNP: rs6053303. As a precaution, however, it should be noted that rs6053303 was homozygous in one of the Control Genomes; possibly this individual has presently undiagnosed Affective Disorder. Hannon's findings may be conveniently expressed (Table 1-3)

\begin{tabular}{|l|l|}
\hline PGP huRef & Is SNP rs6053303 Homozygous? \\
\hline hu3CAB43 & Absent \\
\hline hu4C20BC & Homozygous \\
\hline huEC6EEC & Homozygous \\
\hline
\end{tabular}

Table 1: Major depression SNPs

\begin{tabular}{|l|l|}
\hline PGP huRef & Is SNP rs6053303 Homozygous? \\
\hline hu79E3C7 & Homozygous \\
\hline hu443DE9 & Absent \\
\hline
\end{tabular}


Page 2 of 2

\begin{tabular}{|l|l|}
\hline huAE4A11 & Absent \\
\hline huE8E4FC & Homozygous \\
\hline
\end{tabular}

Table 2: Bipolar disorder SNPs

\begin{tabular}{|l|l|}
\hline PGP huRef & Is SNP rs6053303 Homozygous? \\
\hline hu34D5B9 & Absent \\
\hline hu43860C & Absent \\
\hline huFAA0CF & Homozygous \\
\hline
\end{tabular}

Table 3: Control SNPs

Interestingly, the SNP rs6053303 may be homozygous in both of the Affective Disorders (Endogenous Depression and Bipolar Disorder), indicating that the Depressive Psychosis which may be expressed in both Affective Disorders may have the same genetic cause: namely, the homozygous presence of the SNP rs6053303. This SNP may result in the Prokineticin 2 Receptor being unable to bind, internalise, and ultimately degrade (via the lysosomes) the Depression-causing Prokineticin 2.

The role of the Environment (as opposed to Genetic Predisposition) in the Affective Disorders is apparent in Tables 1 and 2 of Hannon's findings; rs6053233 isn't present in the hu3CAB43, hu443DE9 or huAE4A11 Genomes, indicating that these Psychoses are Reactive (caused by the Environment).

To assist Researchers in confirming the tentative findings of Hannon's (small) in silico Study, potential sources for ELISA Kits to assay bloodstream Prokineticin 1 and Prokineticin 2 are referenced.

\section{A Potential mRNA Treatment for the Affective Disorders}

As mentioned in the abstract, Lorenz et al. have deduced that lipid raft-based scavenger receptors can internalise exogenous mRNA; most is degraded by the endosomes, but some is translated into functioning protein.
Prokineticin 2 Receptor (PROKR2) mRNA has been sequenced and published by NCBI; its Accession Number is: NM_144773.2

The Patent status of this sequence is unknown; its NCBI submission record is $\mathrm{AB} 084081$.

Intravenous administration of the PROKR2 mRNA should restore Prokineticin 2 Receptor function and therefore control both of the Affective Disorders (Endogenous Depression and Bipolar Disorder) [6-9].

\section{References}

1. Cheng MY, Bullock CM, Lee AG, Bermak JC, Belluzzi J, et al. (2002) Prokineticin 2 transmits the behavioural circadian rhythm of the suprachiasmatic nucleus. Nature 23: 405-410.

2. Soga T, Matsumoto S, Oda T, Saito T, Hiyama H, et al. (2002) Molecular cloning and characterization of prokineticin receptors. Biochim Biophys Acta 2-3: 173-179.

3. Martin C, Balasubramanian R, Dwyer AA, Au MG, Sidis Y, et al. (2011) The role of the prokineticin 2 pathway in human reproduction: evidence from the study of human and murine gene mutations. Endocr Rev 2: 225-246.

4. Kishi T, Kitajima T, Tsunoka T, Okumura T, Ikeda M, et al. (2009) Possible association of prokineticin 2 receptor gene (PROKR2) with mood disorders in the Japanese population. Neuromolecular Med 2: 114-122.

5. Li JD, Hu WP, Zhou QY (2009) Disruption of the circadian output molecule prokineticin 2 results in anxiolytic and anti-depressant-like effects in mice. Neuropsychopharmacology 2: 367-373.

6. http://www.mybiosource.com/prods/ELISA-Kit/Human/prokineticin 1/ PROK1/datasheet.php?products_id=703707

7. http://www.mybiosource.com/prods/ELISA-Kit/Human/prokineticin 2/ PROK2/datasheet.php?products_id=940962

8. Dode C, Teixeira L, Levilliers J, Fouveaut C, Bouchard P, et al. (2006) Kallmann Syndrome: Mutations in the Genes Encoding Prokineticin-2 and Prokineticin Receptor-2. PLOS Genet 10.

9. Lorenz C, Fotin-Mieczec M, Roth G, Becker C, Dam TC, et al. (2011) Protein expression from exogenous mRNA: uptake by receptor-mediated endocytosis and trafficking via the lysosomal pathway. RNA Biol 4: 627-636. 